\title{
Engineering and physical education in optics at Kiev National University (Ukraine) on the way of switch over to three-step training
}

Igor Shaikevich

Igor A. Shaikevich, "Engineering and physical education in optics at Kiev National University (Ukraine) on the way of switch over to three-step training," Proc. SPIE 2525, 1995 International Conference on Education in Optics, (13 October 1995); doi: 10.1117/12.224067

SPIE Event: SPIE's 1995 International Symposium on Optical Science, Engineering, and Instrumentation, 1995, San Diego, CA, United States 


\title{
ENGINEERING AND PHYSICAL EDUCATION IN OPTICS AT KIEV NATIONAL UNIVERSITY'(UKRAINE) ON THE WAY OF SWITCH-OVER TO THREE-STEP TRAINING
}

\author{
Igor Shaikevich \\ Taras Shevchenko National University, \\ Department of Physics, Chair of Optics, Kiev, Ukraine
}

\begin{abstract}
$\underline{\text { ABSTRACT }}$
The system of education bachelors, specialists and masters Sci in optics in Taras Shevchenko Kiev National University by fundamental courses of the physics and mathematics also by special courses there was considered. The system of education the masters Sci is discussed.

\section{$\underline{\text { INTRODUCTION }}$}

Nowadays Ukraine turns to new three-step system of education including training of bachelors (4 year education), specialists (1 to 1,5 year education after getting baccalaureate) and masters Sci. The previous educational system provided for training only specialists during 5 to 5,5 years with following training the best of them in post-graduate corse during 3 years with following defence of a candidate thesis. This paper states the system of training bachelors, specialists and masters Sci at Kiev National University on speciality of "Optical and Optoelectronic Systems". It is necessary to note that in contrast to similar training of specialists in optics at technological institutes the students of optics at Kiev University get complete physical and mathematical training according to curriculum of the Department of Physics in addition to technological knowledge.
\end{abstract}

\section{BACHELOR TRAINING}

So far as training of bachelors on "Optical and Optoelectronic Systems" goes on during 4 years as well as that for bachelors of physics it was necessary to reduce a little the number of hours for fundamental optics and spectroscopy courses for the purpose to remain complete fundamental training of bachelors on physics and mathematics in the volume of curriculum of the Department of Physics and simultaneously to introduce a number of purely technological and optical subjects. But this reduction did not touch the training of specialists during 5 to 5.5 years which will be described below. General training of bachelors on optics includes courses of mathematics, general experimental physics, theoretical physics and the humanities. Mathematic training includes 475 hours of mathematical analysis (1-st and 2-nd years), 157 hours of analytical geometry and higher algebra (1-st year), 159 hours of fundamental and integral equations (1-st and 2-nd years), 54 hours of bases of vector and tensor analysis (2-nd year), 81 hours of the function of complex variables (2-nd year), 184 hours of mathematical physics methods (2-nd and 3-rd years), 76 hours of probability theory and mathematical statistics (3rd year), and finally 262 hours of programming and mathematical simulation (1-st and 2-nd years). Approximately 1/3 of 
above mentioned hours is allotted for lectures, $1 / 3$ is allotted for seminars, and the last $1 / 3$ is allotted for independent work of students.

The training of general experimental physics includes 189 hours of mechanics (1-st year), 179 hours of molecular physics (1-st year), 216 hour of electricity and magnetism (2-nd year), 204 hours of optics (2-nd year), 198 hours of atomic physics (3-rd year), 153 hours of nuclear and elementary particle physics (3-rd year), and finally 153 hours of radioelectronics (2-nd year). Distribution of hours on physics includes laboratory works besides lectures, seminars, and independent work. Exemplary distribution of hours is following: 1/3 is allotted for lectures, 1/3 is allotted for seminars and laboratory works, and $1 / 3$ is allotted for independent work of students. The course of theoretical physics consists of theoretical mechanics (210 hours, 2-nd year), electrodynamics (210 hours, 2-nd and 3-rd years), quantum mechanics (235 hours, 3-rd year), Thermodynamics and statistical physics (184 hours, 3-rd and 4-th years). Distribution of hours for lectures, seminars and independent work is approximately equal to $1 / 3$.

Humanities education includes such subjects as history of Ukraine, culture, philosophy, bases of economical theories, bases of law, sociology, foreign languages, bases of ecology and safety of vital functions, religion science and etc.

Special training of optics begins from the first year. First of all it is engineering graphics of 35 hours (1-st year). Then there are calculation of optical systems (54 hours, 2-nd year), and technology of optical instrument engineering (54 hours, 3-rd year). This cycie of subjects ends with course work being fulfilled and defended by each student on him own.

In 3-rd year students attend also lectures on bases of designing of optical instruments (51 hours) and methods of spectroscopic investigations (34 hours). In 4-th year the education of speciality is represented more widely. Students attend courses of optical metrology and standardization (36 hours), optoelectronic instruments and systems ( 86 hours), modern methods of interferometry ( 54 hours), diffraction theory of images (32 hours), physics of semiconductors ( 36 hours), spectroscopy of atoms and molecules ( 36 hours), polarization methods of measurements and polarization instruments (48 hours), optical material science ( 32 hours), physical bases of laser radiation control (32 hours), and optical detection and ranging ( 32 hours). The last two special courses are given at the chair's branches at PO "Arsenal" and NPO "Kvant". In addition, in 4-th year students may attend special courses for choise such as optophysical methods in medicine and biology and optophysical instruments in medicine and biology. The number of hours stated for all special courses are allotted only for lectures. Approximately the same number of hours are allotted also for laboratory works and independent work of students. In 4-th year students do practical work at the Chair's branches at PO "Arsenal", NPO "Kvant", and Semiconductor Physics Institute of National Academy of Sciences of Ukraine, and finish educational cycle with defence of final work. Final works are fulfilled according to subject-matter of scientific researches carried out by the Chair of Optics and themes of its branches.

\section{SPECIALIST TRAINING}

Training of specialists lasts some more period of 1.5 years after finishing education for bachelor's degree, i.e. 5.5 years in all. As it has been stated above at training specialists the main emphasis is made on fundamental opto-physical 
lecture courses. They are spectroscopy of crystals ( 54 hours), laser spectroscopy ( 57 hours), applied quantum electronics (54 hours), electromagnetoacoustic optics (54 hours), calculation methods in physics and jointing of computers with optoelectronic instruments (60 hours), coherent optics and holography (58 hours) optical diagnostics of semiconductors (54 hours), optics of natural media (54 hours), and bases of optical communication, integral and fiber optics (60 hours). Attended is also course of economics and management ( 36 hours). The last half of training year is devoted mainly to independent scientific investigations to fulfil diploma work. Themes of diploma works are quite various and go with either themes of the Chair of Optics researches or themes of the Chair's branches. Before fulfilling diploma works students do prediploma practice.

The defence of diploma works is carried out before state examination commission. A chairman of the commission (as a rule a famous scientist) is invited from other scientific institution.

\section{MASTER SCI TRAINING}

It must be noted right away that opinion concerning master Sci training at Kiev National University including the speciality of "Optoelectronic Instruments and Systems" does not become formed finally. There are some points of view on this problem.

The first point of view provides master Sci training during 1 to 2 years after training of specialists. The main emphasis is made on independent scientific work and courses of pedagogical psychological subjects, and also on modern achievements in the field of physics and optics. This point of view as a matter of fact equates master Sci training with that which was called earlier as probation period before post-graduate study. The second point of view envisages the substitution of post-graduate course by master Sci training during 3 years with following defence of master Sci (former candidate) dissertation. And finally the third point of view envisages the jointing of specialist and master Sci trainings. Master Sci degree is given according to this point of view to those graduating students who show high knowledge during study process and whose diploma works are fulfilled on high scientific level with following publication.

The nearest future will show victorious point of view. 